\title{
Education as an Implementation Factor of the Sustainable Development of the Society
}

\author{
Anastasia Nasibulina \\ Postgraduate Student, Research fellow, International UNESCO Chair in Environmental Ethics \\ East Siberia State University of Technology and Management; dn.nastia@gmail.com
}

\author{
Doi:10.5901/mjss.2015.v6n6s5p262
}

\begin{abstract}
The topicality of a socio-philosophical study of education as an implementation factor of the sustainable development of the society is preconditioned by the fact that the reflected and substantiated understanding of both the axiology of contemporary education, its ability to exert influence on the spiritual and moral priorities of personality, and actualization of the sustainable societal development in the 21 st century depend on the educational system. In modern world the search for alternative ways of social development and the problem of understanding of the adaptation of the society to a new reality in all its multidimensionality reached global dimensions. Among a number of possible alternative directions of social development the concept of sustainable development stands apart. This paper aims to study the role of education in the implementation of the sustainable development strategy and analyze the modern state of education in the interest of sustainable development (ESD). To attain the set goal an aggregate of mutually reinforcing research methods was used: study of scientific and regulatory sources, analysis and generalization of pedagogic experience and expert assessment. In author's opinion the ESD is one of the most efficient methods of implementation of sustainable development principles by forming new thinking and behavior.
\end{abstract}

Keywords: sustainable development, education for sustainable development, Global Action Program, Baikal region.

\section{Introduction}

The level of attention to the problem of sustainable development remains high in the world over the entire period after the United Nations Conference on Environment and Development in 1992, historical for the human civilization. It is also characterized by a consistent pattern: the more the attention to promotion of sustainable development ideas in a certain country is the higher are its indicators of social and economic development. Traditionally, education, since recently a priority factor of progress in the human society, plays an important role in the promotion of these ideas.

Nowadays, it is practically a commonly accepted truth that the leading role in the achievement of sustainable development is to be played by education. In many UN documents education is directly referred to as a "decisive factor of change." A broad acknowledgement of education and closely associated upbringing and enlightenment as the decisive factor of transition to sustainable development stipulated the emergence of a phenomenon of education for sustainable development at the turn of the century. A new civilizational phenomenon turned out to be a natural development of the sustainable development concept adopted in 1992 as a global development strategy.

An absolute majority of the countries of the world perceived the ideas of a new educational paradigm with interest. At present they actively participate in the UN-announced Decade of Education for Sustainable Development (DESD, 2005-2014). This participation is manifested in various forms and reflects the specificity of certain countries, historical features of educational system development, national policy priorities and other factors. The formation of strategic planning in a form of ESD infrastructure, in which decisions at the national level play an important role, became common for most of these countries. Such documents have already been adopted in many countries of the world and they turned into an important organizing factor of implementation of state-of-the-art innovative educational technologies suited to face challenges of the day. An active work to form an ESD system is underway in the world. In the developed countries it resulted in an impressive development of its institutional foundations and provision of state support.

The acceptance of a global ESD project by the humanity is a unique opportunity to upgrade the status of education as a civilizational institution. Besides, it is a real chance to demonstrate the potential of science to the contemporary society and broad introduction into it of environmental culture as a necessary element of the system of knowledge and skills providing real sustainability and well-being of the social medium. 


\section{Research Methodology and Design}

The main goal of this paper is to study the role of education in the implementation of a global development strategy. This goal stipulated the setting and solution of the following issues: study the historical stages of development and formation of the ESD system; analyze the contemporary condition of the ESD, in particular, to determine the main vectors of development and mark the results of the already completed work in the field of the ESD. I also aim to expose weak sides that require additional work taking into account the strategic meaning of the Baikal region in the implementation of the global strategy of sustainable development. To achieve this it is necessary to study the ESD policy carried out in this region.

To attain the set goal an aggregate of mutually reinforcing research methods was used: study of scientific and regulatory sources, analysis and generalization of pedagogic experience and expert assessment. This study also uses elements of comparative analysis methodology, systemic and interdisciplinary approach.

\section{Results and Discussion}

\subsection{Education for sustainable development}

Sustainability requires a change in our attitude to production and consumption. In essence, it demands new ways of thinking and behavior in the tideway of global civic consciousness, and new values, skills and knowledge. That is why education for sustainable development should take a central position in a new global agenda in the field of development, currently formed at governmental level.

First and foremost, it is necessary to view the origins of the ESD concept and its original goals. In 1987 the UN member states approved the Brundtland Report entitled "Our Common Future", which recommended accepting a new concept of global cooperation and future development of the world.

This concept was sustainable development, "which meets the requirements of the present, but does not endanger the ability of the future generations to meet their own needs." (World Commission on Environment and Development, 1987). In this connection an important question was raised: how can the world switch from the capitalist development paradigm to sustainable development so that the future generations would also adhere to it.

The "Agenda 21" was passed, according to which the countries should come to an agreement and work out the strategy for the implementation of sustainable development. The document consists of four sections and 40 themes on which the countries came to a consensus.

1. Social and economic dimensions.

2. Environmental issues.

3. New main population groups involved in the program.

4. Means of implementation. (United Nations, 1993)

The term and notion of ESD was mentioned in the "Means of Implementation" section, chapter 36 "Promoting education, public awareness and training." It specifically highlighted the role that these three components may play in the implementation of the sustainable development principles. Also ESD is mentioned in all chapters of "Agenda 21" and is repeatedly mentioned in the UN Conventions on climate change, loss of biodiversity, desertification, woodland protection and at all UN conferences. It is necessary to involve all available education systems to educate a new generation of the new world citizen for the globe to shift from the unsustainable development paradigm to sustainable development.

The Johannesburg Summit held in September 2002 also proposed to consider education for sustainable development as one of the priorities for the activity of the world community. Highly assessing and supporting this initiative the United Nations Organization declared the UN Decade of Education for Sustainable Development (2005-2014). Based on the results of the Decade of Education for Sustainable Development the UNESCO expert group developed the Global Programme (GAP) to transform the DESD into an institutional process after 2014 (Proposal for a Global Action Program on Education for Sustainable Development, 2014). This programme was developed taking into account the DESD experience, previous UN reports on various educational issues, and on the basis of broad consultation with representatives of state and non-governmental organizations from over 100 countries. After thorough discussions the Global Action Programme was approved at the World Conference on ESD held in November 2014 in Aichi-Nagoya (Japan). In June 2015 the International Conference on ESD was held in Khanty-Mansyisk (Russian Federation). The main goal of the conference was in definition of the ways of implementation of the Global Action Programme on ESD. Characteristically, this Conference used an exclusively broad statement of the "sustainable development" problem. Education was viewed as an active system and universal driver capable of providing a balanced development of various 
life spheres of the society.

ESD brings an enormous contribution to education, information and manpower training systems. Through ESD the society begins to understand how to come to a sustainable future. It should be borne in mind that ESD is not a new additional subject or research field, but a new goal of education.

Education for sustainable development is based on such values as justice, equality, tolerance, sufficiency and responsibility. It promotes gender equality, social cohesion and reduction of poverty and complies with the qualities listed in the Earth Charter Initiative - care about the people around, personal integrity, and honesty. ESD is based on the principles that promote a sustainable lifestyle, democracy and well-being of every single man. Protection and restoration of the environment, conservation of natural resources, their sustainable use, and solution of the problems connected with unsustainable production and consumption, and creation of just and peaceful societies are also among the basic ESD principles.

Systems providing quality and innovative education, informing of the population and manpower training contribute to the attainment of a higher life standard and lead to a sustainable future.

\subsection{Principal results of prospects of ESD}

Among the important achievements of the Decade there are, first of all, the wide recognition of education as the most important and irreplaceable factor of sustainable development in the world, and the development of a strategic approach to the development of ESD on the international and national levels.

At present the following main directions of ESD may be singled out:

1. Informing of the society and development of understanding of sustainable development. It becomes clear that a state needs citizens not simply educated and enlightened in the issues of sustainable development, but also understanding their role in its implementation. A government needs a solid society and political support to replace the existing legislation by a better one, and manufacturers need consumers who can realize broader consequences of their purchases. These components are crucial in the new forming concept of a "Global Citizen."

2. Implementation of professional training programs on all levels. More environmentally safe workplaces, advent of a new legislation, code of regulations, norms, statutes and technologies lead to the necessity of access to lifetime education for employees and managers in private and public sectors. This fourth direction of ESD connected with the informal education and training of cadres needs cooperation with the institutes of formal education and industry in order to ensure the influx of new employees armed with the state-of-the-art knowledge and cutting edge skills to the industry.

3. Provision of access to and getting of quality education. Without educated citizen there will be neither sustainable development, nor development in general. Hence, one of the main goals is to provide most people with quality education. Each country should determine aspects of quality education for itself. The difference of ESD from the "Education for All" (EFA) program lies in the fact that ESD is not limited to the developing countries only. The principles of ESD are applicable to all countries since in all states there are a certain percentage of students unable to get proper education for this or that reason and eventually end up nondemanded and unemployed. The main goal and priority of all formal educational systems throughout the world is to ensure the accessibility of quality education for all citizens. Besides, this provision is one of the key human rights.

4. Reiteration of the existing educational programs in the benefit of sustainable development. The bulk of educational programs were worked out with a developmental bias, which is diametrically opposed to sustainable development. It turned out that the most developed countries with a high level of education pose the major threat to sustainable future. Hence the Aichi-Nagoya Declaration appeals to various nations to reconsider goals and values in the foundations of their educational systems in order to take a new look on the implementation of sustainable development principles in education. Such transformation of the entire educational system presupposes huge changes and is a tremendous task, which should be solved to get the desired result.

Success in the implementation of sustainable development ideas, environmentalization and socialization of all sides of life depends on active position and personal motivation of every individual. This determines the necessity of educational and outreach activities, targeted work of mass media, social advertisement and the sphere of culture. It is the level of culture that determines the environmentalism of behavior, choice in favor of knowledge economy and understanding of the necessity to immediately solve social problems. Principal role in the provision of ideas about modern 
development priorities in the system of education and training belongs to civic society and expert community. The Inchon Declaration (2014, South Korea) tells that "quality education not only plants knowledge, but develops creative abilities and ensures development of analytical, cognitive, interpersonal and social skills and competence to solve set objectives alongside with reading, writing and calculus. Education should develop skills and competence and plant values necessary for the society members to lead a full and healthy lifestyle, be capable of decision-making and reacting to local and global problems and objectives with the help of "Education for Sustainable Development" and "Global Citizenship Education" programmes" (Incheon Declaration, 2015).

The concluding report of the UN Decade of Education for Sustainable Development contains the following most important conclusions made using the data based on the results of ten years of work of the program throughout the world:

1. Educational systems turned their faces to the solution of the sustainable development problems. In many countries nowadays a sustainable tendency of raising the role of education in the solution of social, environmental and economic problems that the world already faces or will encounter in the future may be observed.

2. The process of rapprochement of the agendas in the sphere of development and education is underway. Education, information and outreach activity and training is more and more often used by stakeholders as means of promoting sustainable development.

3. Political leadership proved its necessity by facilitating the formation of organizational conditions necessary to carry our transformations.

4. High efficiency of multistakeholder partnership. Carrying out of the DESD contributed to raising the significance of partnership connections and cooperation between stakeholders. The growing network interactions in the field of ESD between universities in various countries allowed mobilizing the global community and establish mutual assistance for the implementation of ESD.

5. Growing local interest in ESD. Implementation of ESD today includes a number of elements relevant to local context.

6. Application of general institutional approaches in the field of ESD. General institutional approaches are increasingly put into effect and help the students bring their contribution to sustainable development at school or university, in the inner circle and at workplace.

7. ESD contributes to the development of interactive, student-oriented teaching methods. Teaching methods based on active involvement of students, training of critical thinking and problem-oriented education, as the experience shows, are most suited to the development of ESD. Instructors on all levels of education play the key role in this process.

8. Integration of ESD in the system of formal education. At the level of political decision-making there is a growing understanding of the fact that upbringing and education of young children are the foundations of sustainable development. Political attention to the introduction of ESD into the nursery and junior high school curricula is specifically high. The recent decade was notable for the expansion of efforts in the field of sustainable development at the level of higher education.

9. Entrenchment of ESD principles in the non-formal or informal educational systems. Local communities, families and separate citizens of many countries today more clearly understand at everyday level the problems of environment and sustainable development.

10. Vocational and technical education and professional training assist in promotion of sustainable development. International policy and planning in the field of sustainable development and policy and planning in the sphere of vocational and technical education and training are aimed at the development of "green" economy and environmentalization of skills opening new prospects for the studies and contribute to efforts to boost the potential.

Despite successes attained within the frameworks of DESD there are still some serious problems, which only will be solved for the use of the full ESD potential. Among them are:

- Identification of problems and prospects of implementation of the global program of DESD transformation into the institutional process and a necessity of further institutional entrenchment of ESD;

- Comprehensive understanding of new pedagogical realities associated with the formation of environmentally oriented worldview and environmental culture at various levels of education, substantiation and statement of relevant pedagogical tasks;

- Necessity of carrying out of additional studies, conducting monitoring and assessment, development and introduction of efficient methodologies, innovative teaching tools (information technologies, audio-video programmes, textbooks and study guides) for the solution of educational reform issues in the benefit of 
sustainable development;

- Necessity of further coordination of efforts in the field of education and in sustainable development sectors;

For the solution of these issues the Global Action Programme will focus on the expansion of activities and their scope. To provide the strategic direction and deeper involvement of stakeholders in the GAP five priority spheres of activity to promote the ESD agenda were identified.

1. Support at the political level. Large-scale introduction of ESD principles in the educational policy and policy in the field of favorable conditions for the implementation of ESD principles and provision of systemic changes.

2. Reform of the educational sphere and vocational training. Integration of sustainable development principles into the system of education and vocational training.

3. Professional enhancement of educators and trainers. Professional enhancement of educators and trainers for more efficient implementation of ESD.

4. Expansion of rights and possibilities of youth and mobilization of the youth's efforts. Entrenchment of the ESD activity among the youth.

5. Accelerated introduction of sustainable decisions at the local level. Expansion of the scale of implemented programs and network interaction in the sphere of ESD at the local level.

In general, the completed Decade of Education for Sustainable Development may be viewed as a considerable prerequisite of forming culture of sustainable development. Objectives set during it are, in many respects, ponderous and require a new approach and understanding. First and foremost, this concerns efficiency improvement of education reform in the benefit of sustainable development and development of an adequate management system for this project.

\subsection{Implementation of ESD principles in the Baikal region (a case study of East Siberia State University of Technology and Management)}

In the course of the UN Decade of Education for Sustainable Development, on the basis of the analysis of national and international educational practices and experience of activities of educational establishments an ESD strategy for the Baikal region was developed. In the East Siberia State University of Technology and Management the transformation of the existing educational system at all levels in the benefit of sustainable development commenced with the foundation of the Institute for Sustainable Development as an educational subsidiary of the university in 1998. The existing curricula were supplemented by environmental and ethical disciplines aimed at forming of environmental culture. In particular, they were courses such as "Ecology and Ethics", "Sustainable Development in the Context of the Philosophy of Science" and "Sociocultural Problems of Sustainable Development." The concept of "Noospheric Strategies and Technologies of Sustainable Development in the Process of Modernization of Higher Education" is in the process of development.

One of the main directions of the university's activity is training of specialists capable of not simply properly fulfilling the assigned tasks (provided by supporting education), but also able to generate goals and propose creatively different solution approaches, capable of multi-variant analysis of information streams by new methods. According to the Strategic Development Program of the East Siberia State University of Technology and Management for 2011-2015 the mission of the university is promotion of sustainable socioeconomic development of the Baikal region and international integration of Russia by introducing and rendering of high quality educational services, development of scientific schools and innovation technologies.

The UNESCO Chair in Environmental Ethics made a significant contribution to the development of ESD system. In particular, the chair works on axiological foundations of environmental ethics and Noospheric strategy of education for sustainable development (a case study of the Baikal Natural Territory).

One of the most important objectives of the chair is the promotion of environmental ethics themes in teaching of social, natural and technical sciences and assistance in the development of environmental ethics education in higher and secondary schools. The results of the research activity conducted by the faculty are actively introduced into the educational process. Training programs for specialists in various fields based on the sustainable development principles and environmental ethics are designed in cooperation with other departments and institutes of the university. Study packs and educational programs are oriented towards the formation of careful and moral attitude to nature (Nasibulina, 2014).

Special attention is paid to the formation of environmental culture and environmental ethics.

Environmental ethics is a teaching about co-evolutionary relationships of human beings with the environment based on the perception of nature as a moral partner as well as equal value and equality of all living beings. According to the environmental-ethical concept of the noosphere the main objective of environmental ethics is to construct a system of value and normative paradigms of the society that determine harmonious relations of man and nature. Attainment of this goal presupposes solution of the main issues of the sustainable development of the humanity (limitation of 
overconsumption by the rich and eradication of poverty; limitation of material consumption and stimulation of spiritual (scientific, artistic) creative activity as a form of being of man in the world; provision of sustainable use of material and intellectual resources of the society, non-decreasing growth rate of productivity of social and natural systems not only at present, but also in future; preservation of integrity, beauty, diversity and sustainability of all environmental systems of planet Earth). The axiological reorientation of the society is aimed at overcoming the consumerist intentions of the industrial civilization (Saktoev, Mantatov, 2010).

According to the "Concept of Transfer of the Russian Federation to Sustainable Development", "the movement of the humanity towards sustainable development will, in the final analysis, lead to the formation of the intelligence sphere (noosphere), when spiritual values and knowledge of the humanity living in harmony with the environment will become a measure of national and individual wealth." (Concept of Sustainable Development for the Russian Federation, 1996). Environmental ethics is not only and not so much an ethics of the environment, but an ethics of the spiritual growth of man. We will not solve a single problem until the man himself, his spiritual consciousness, are transformed. Environmental ethics is exactly that phenomenon, which supports the rising evolution of human consciousness.

Nowadays the main task is to develop the axiological foundation of ESD taking into account the local specificity and cultural peculiarities based on the environmentally-oriented worldview enabling every person to acquire knowledge, skills, values and approaches expanding his rights and possibilities for the contribution to the sustainable development, taking competent decisions and carrying out of responsible actions in the name of integrity of the environment, economic expediency and just society for this and future generations.

\section{Conclusion}

Apprehension of the accomplished work testifies to the fact that the process of ESD approached a new stage by the middle of the second decade of the $21^{\text {st }}$ century. In the past the national educational systems had a chance to selfdetermine in the global educational process, carry out public and professional scrutiny of the first attempts and accumulated experience in the field of ESD. A new step toward realization of the necessity of the strategic planning of national routes in the direction of ESD, organization of flexible administration of this process in accordance with social challenges, provision of mechanisms of self-supporting educational process in the benefit of sustainable development is ahead of us. ESD is one of the means of societal and economic modernization since it teaches to think in more modern terms. In the long run it contributes to the preparation of a generation capable of producing innovations.

In conclusion we should return to one of the aforementioned provisions: ESD is not an additional subject or research field, but a new goal of education. If the system is reoriented, the understanding of how to use the current objectives to introduce sustainable development for working out of new requirements and principles will result. Such objectives include: solution of local and global social, economic and environmental problems in such a way so that it would contribute to the formation of a new type of educated man - a "global citizen"; reorientation of science, technology, engineering and mathematical curricula for the solution of real problems of sustainability, and such solutions will contribute to the increased interest of students to the educational process making it more understandable; understanding of how our schools may be better suited to serve the society and, hence, provision of a higher social role of schools and teachers in the society.

The role of reasonable implementation of ESD strategy is in the formation of such skills as creative thinking, higher order thinking, critical thinking, mutual cooperation, and responsibility for actions. It is crucial that the Global Action Program on ESD becomes essential for the conversion and reorientation of the educational system for happy life of the present and future generations.

\section{Acknowledgements}

This work was financially supported by the Russian Science Foundation (№14-18-02006).

\section{References}

Concept of Sustainable Development for the Russian Federation (1996). Moscow.

Incheon Declaration Education 2030: Towards inclusive and equitable quality education and lifelong learning for all (2015).

Nasibulina, A.S. (2014). Obrazovanie v interesah uctoychivogo razvitiya: problemy I perspektivy [Education for sustainable development: achallenges and prospects]. Ekologicheskaya etika i tehnologii ustoichvogo razvitiya v XXI veke. Izdatel'stvo VSGUTU, UlanUde, 280-288. 
Proposal for a Global Action Program on Education for Sustainable Development as follow-up to the United Nations Decade of Education for Sustainable Development (DESD) after 2014.

Saktoev, V.E., Mantatov, V.V. (2010). Tcivilizatcionnye osnovaniya I perspecyivi ustoichivogo razvitiya Baikalskogo regiona [Civilization Foundations and Perspectives of Sustainable Development of the Baikal Region]. Vestnik VSGUTU №2, Ulan-Ude, 103-109. United Nations Agenda 21 (1993).

World Commission on Environment and Development (1987). Our Common Future. Oxford: Oxford University Press, 27. 